\title{
Commentary \\ Selenium supplementation in critically ill patients: can too much of a good thing be a bad thing? \\ Daren K Heyland
}

Clinical Evaluation Research Unit, Angada 4 Kingston General Hospital, Kingston, ON K7L 2V7, Canada

Corresponding author: Daren K Heyland, dkh2@post.queensu.ca

Published: 7 August 2007

Critical Care 2007, 11:153 (doi:10.1186/cc5975)

This article is online at http://ccforum.com/content/11/4/153

(c) 2007 BioMed Central Ltd

See related research by Forceville et al., http://ccforum.com/content/11/4/R73

\begin{abstract}
A recent study by Forceville and colleagues evaluated the effect of high-dose selenium administration as a treatment for septic shock. The study was negative and conflicts with existing clinical data regarding selenium administration in critically ill patients. Perhaps the key to understanding the differences between these discrepant observations lies in considering the dose and timing of selenium administration.
\end{abstract}

Selenium is an essential nutrient for all mammalian species, and in this issue of Critical Care Forceville and colleagues [1] evaluated the effect of high-dose selenium administration as a treatment for septic shock. Low levels of plasma selenium have been observed in critically ill patients and are associated with increased markers of oxidative stress, worse organ failure, and higher mortality rates [2]. Increasing levels of selenium are correlated with increased glutathione peroxidase, a key endogenous antioxidant defense mechanism [3]. These observations have given rise to several studies providing exogenous selenium, at doses less than $1,000 \mu \mathrm{g} /$ day, to critically ill patients. Overall, these antioxidant supplementation strategies are associated with a large beneficial mortality effect (risk ratio (RR) $0.69,95 \%$ confidence interval (Cl) 0.59 to 0.82 ) [4].

However, selenium compounds can also be considered 'prooxidative'. As the authors suggest, the pro-oxidant properties of selenite may be beneficial early in the course of septic shock if they reduce inflammation either by inhibiting the activation of NF- $\mathrm{KB}$ or by inducing a pro-apoptotic effect on activated circulating cells [1]. Nevertheless, at some level, the pro-oxidative effect of selenium may become toxic to humans. Their toxicity is thought to be due to the pro-oxidant ability of selenium compounds to catalyze the oxidation of thiols and simultaneously generate superoxide $\left(\mathrm{O}_{2}{ }^{-}\right)$, thus causing a depletion of intracellular glutathione, excessive oxidative stress, and cell death [5]. The toxicity of selenium is clearly dose dependent and varies depending on the type of selenium compound administered [5].

Forceville and colleagues attempt to take advantage of this dual effect of selenium in treating septic shock by administering a high, pro-oxidant dose $(4,000 \mu \mathrm{g})$ on study day 1 , followed by an antioxidant dose of $1,000 \mu \mathrm{g} /$ day for an additional 9 days. In a randomized trial of 60 patients with severe sepsis, they were unable to detect any treatment effect of this selenium administration strategy. Why do their findings contradict those of the recent meta-analysis [4], which suggests a large decrease in mortality?

Perhaps the underlying rationale is unsound? At a theoretical level, inducing apoptosis of cells causing a maladaptive inflammatory reaction by means of a pro-oxidative mechanism may be beneficial. However, no evidence of any beneficial anti-inflammatory effect of high-dose selenium is provided, either in the study by Forceville and colleagues or in any other published study of septic patients or in septic animal models. In contrast, inducing apoptosis of beneficial cell lines (such as intestinal epithelial cells) may be harmful. Perhaps a high dose (more than $1,000 \mu \mathrm{g} /$ day) of selenium increases oxidative stress and leads to glutathione depletion and increased cell death. This dosing strategy may therefore actually be harmful, negating or overwhelming any beneficial effect of a subsequent lower-dose selenium administration. Support for this assertion comes from the fact that the incidence of multiorgan failure in selenium-treated patients in the Forceville study was more than double that of patients in the control group (32\% versus $14 \%, P=0.09$ ). This large treatment effect lacked statistical significance because of the small sample size, but it should not be ignored. 
Figure 1

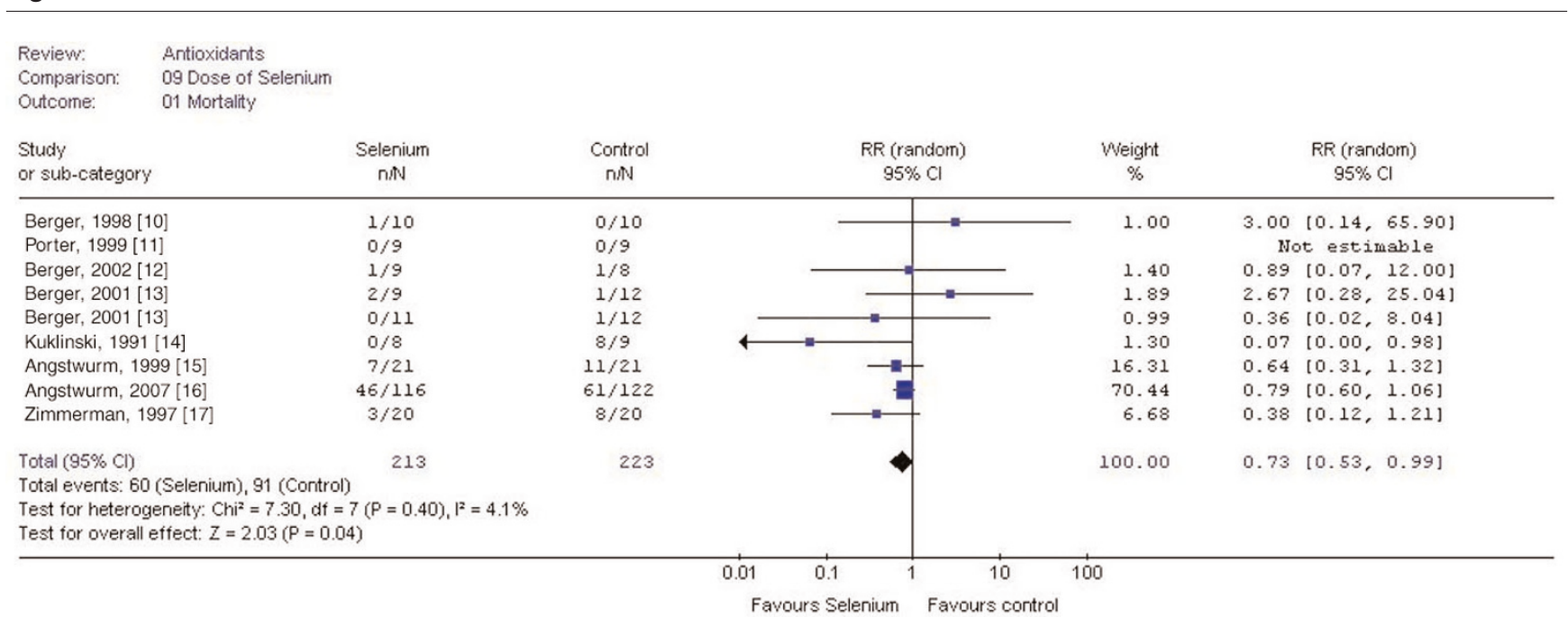

Effect of selenium on mortality: dose-response curve. Studies are listed in order of the dose of selenium. Cl, confidence interval; RR, risk ratio.

Perhaps the timeliness of the study interventions may have affected the study results. On average, the study medications were started 24 hours after admission to the intensive care unit. Thus, more than $50 \%$ of patients would have had their study medication started more than 24 hours after the onset of shock. There is some evidence that oxidative stress leading to mitochondrial dysfunction becomes irreversible within 6 to 24 hours after the onset of tissue hypoxia $[6,7]$. Thus, for antioxidant strategies to be effective, they must be administered as soon as possible after the onset of shock.

So what is the optimal dose of selenium in critically ill patients in shock? The meta-analysis we published in 2005 suggests that studies using a higher dosing strategy of selenium (more than $500 \mu \mathrm{g} /$ day) showed a tendency towards a decrease in mortality (RR $0.52,95 \% \mathrm{Cl} 0.24$ to $1.14, P=0.10$ ), whereas studies that used a lower dose did not demonstrate any effect on mortality (RR 1.47, 95\% Cl 0.20 to 10.78, $P=0.70$ ) [2]. These data have been updated with recent evidence that seems to suggest that the higher the dose, the more likely is a positive treatment effect on mortality (see Figure 1, which shows that low-dose studies starting at the top are associated with negative or no treatment effect and that the higher-dose studies at the bottom tend towards a positive treatment effect). Building on these data, we recently published the first dosing study of its kind that asked this specific question: What is the optimal dose of selenium and other antioxidants in critically ill patients? We studied a range of doses of selenium from 0 to $800 \mu \mathrm{g} /$ day in a series of critically ill patients with either septic or cardiogenic shock [8]. We measured the effect of the various doses of selenium and other antioxidants on glutathione, thiobarbiturate acidreducing substrates (TBARS), mitochondrial function, and organ failure. This study was designed as a safety study, and as we escalated the dose of selenium to $800 \mu \mathrm{g} /$ day we observed no deterioration in organ function. More importantly, we observed greater preservation of glutathione (greater antioxidant capacity), fewer TBARS (less oxidative stress), and improved mitochondrial function.

Our main inference from this dosing-optimizing study was that supplementation with $800 \mu \mathrm{g}$ of selenium (in combination with other antioxidants) was safe. We are now moving forward with a large-scale multicenter trial of 1,200 patients to evaluate whether such a dose has a positive effect on mortality [9]. The answer to the question posed above will therefore have to wait for the completion of this study, but in the mean time I suggest that doses greater than $1,000 \mu \mathrm{g} /$ day could be harmful and doses less than $800 \mu \mathrm{g} /$ day may not be optimal in critically ill patients.

\section{Competing interests}

The author declares that they have no competing interests.

\section{References}

1. Forceville X, Laviolle B, Annane D, Vitoux D, Bleichner G, Korach J-M, Cantais E, Georges H, Soubirou J-L, Combes A, Bellissant EB: Effects of high doses of selenium, as sodium selenite, in septic shock: a placebo-controlled, randomized, double-blind, phase II study. Crit Care 2007, 11:R73.

2. Heyland DK, Dhaliwal R, Suchner U, Berger M: Antioxidant nutrients: a systematic review of vitamins and trace elements in the critically ill patient. Int Care Med 2005, 31:327-337.

3. Berger MM, Baines M, Chiolero R, Wardle CA, Cayeux C, Shenkin A: Influence of early trace element and vitamin E supplements on antioxidant status after major trauma: a controlled trial. Nutr Res 2001, 21:41-54.

4. http://www.criticalcarenutrition.com

5. Spallholz JE: On the nature of selenium toxicity and carcinostatic activity. Free Radic Biol Med 1994, 17:45-64.

6. Suliman HB, Welty-Wolf KE, Carraway MS, Tatro L, Pianttadosi CA: Lipopolysaccharide induces oxidative cardiac mitochondrial damage and biogenesis. Cardiovasc Res 2004, 64:279-288. 
7. Frost MT, Wang Q, Moncada S, Singer M: Hypoxia accelerates nitric oxide-dependent inhibition of mitochondrial complex 1 in activated macrophages. Am J Physiol Regul Integr Comp Physiol 2005, 288:R394-R400.

8. Heyland DK, Dhaliwal R, Day A, Drover J, Cote H, Wischmeyer P: Optimizing the dose of glutamine dipeptides and antioxidants in critically ill patients: a phase I dose-finding study. J Parenteral Enteral Nutr 2007, 31:109-118.

9. Heyland DK, Dhaliwal R, Day AG, Muscedere J, Drover J, Suchner U, Cook D; Canadian Critical Care Trials Group: REducing Deaths due to OXidative Stress (The REDOXS Study): rationale and study design for a randomized trial of glutamine and antioxidant supplementation in critically-ill patients. Proc Nutr Soc 2006, 65:250-263.

10. Berger MM, Spertini F, Shenkin A, Wardle C, Wiesner L, Schindler C, Chioléro RL: Trace element supplementation modulates pulmonary infection rates after major burns: a double-blind, placebo-controlled trial. Am J Clin Nutr 1998, 68: 365-371

11. Porter JM, Ivatury RR, Azimuddin K, Swami R: Antioxidant therapy in the prevention of organ dysfunction syndrome and infectious complications after trauma: early results of a prospective randomized study. Am Surg 1999, 65:478-483

12. Berger MM, Baines $M$, Wardle CA, Cayeux MC, Chiolero R, Shenkin A: Trace element supplements modulate tissue levels, antioxidant status and clinical course after major burns preliminary results. Clin Nutr 2002, 21(Suppl 1):66

13. Berger MM, Recmond MJ, Shenkin A, Rey F, Wardle C, Cayeux C, Schindler C, Chiolero: Influence of selenium supplements on the post-traumatic alterations of the thyroid axis: a placebo-controlled trial. Intensive Care Med 2001, 27:91-100

14. Kuklinski B, Buchner M, Schweder R, Nagel R: Akute Pancreatitis-eine "Free Radical Disease:. Letalitatssenkung durch Natriumselenit (Na2SeO3)-Therapie. Z Gestame Inn Med 1991, 46: S145-149

15. Angstwurm MW, Schottdorf J, Schopohl J, Gaertner R: Selenium replacement in patients with severe systemic inflammatory response syndrome improves clinical outcome. Crit Care Med 1999, 27:1807-1813

16. Angstwurm MW, Engelmann L, Zimmermann T, Lehmann $C$, et al.: Selenium in Intensive Care (SIC): results of a prospective randomized, placebo-controlled, multiple-center study in patients with severe systemic inflammatory response syndrome, sepsis, and septic shock. Crit Care Med 2007, 35:118-26.

17. Zimmermann T, Albrecht S, Kühne H, Vogelsang U, Grützmann R, Kopprasch S: Selensubstitution bei Sepsispatienten. Med Klin 1997, 92(SuppI III):3-4 